\title{
Helicobacter pylori: Neurological and Ophthalmological Disorders
}

\author{
Muhammad U. Farooq ${ }^{1}$
}

Archit Bhatt ${ }^{l}$

\begin{abstract}
Helicobacter pylori infection has been associated with many intestinal and extraintestinal infections. It has been linked with many neurological and ophthalmological disorders including cerebrovascular diseases, migraine, Alzheimer's disease, epilepsy, Parkinson's disease, multiple sclerosis, peripheral neuropathies, glaucoma, and non-arteritic anterior ischemic optic neuropathy. The pathophysiological mechanisms could involve various immunological processes in response to an infectious agent or different antigens released during tissue destruction resulting in activation of cellular and humoral immunity; platelet activation and aggregation; different vasoactive and inflammatory substances; reactive oxygen species; and apoptotic processes. The long-term effects of H. pylori eradication therapy on the course of these disorders still need to be explored and warrant further studies.
\end{abstract}

Keywords: Helicobacter pylori - Cerebrovascular diseases - Alzheimer's disease - Parkinsn's Disease - Migraine - Seizure disorders-Multiple sclerosis-Peripheral neuropathies-Glaucoma.

\section{INTRODUCTION}

Helicobacter pylori (H. pylori) is a microaerophilic, spiral shaped, Gram-negative bacterium that colonizes the gastric mucosa of more than half humans worldwide. It has been associated with many intestinal and extraintestinal infections ${ }^{1-3}$. A high $H$. pylori seroprevalance has been reported in different neurological and ophthalmological disorders including cerebrovascular diseases, mild cognitive impairment, Alzheimer's disease, Parkinson's disease, seizure disorders, migraine, multiple sclerosis, peripheral neuropathies, GuillainBarre syndrome, and glaucoma. We discuss the role of $H$. pylori in these neurological and ophthalmological disorders in this review article.

\section{THE ROLE OF H PYLORI IN NEUROLOGICAL AND OPHTHALMO- LOGICAL DISORDERS}

\section{Cerebrovascular disorders}

H. pylori is considered to be a stroke risk factor. Chronic H pylori infection seems to be more prevalent in stroke patients than in healthy population ${ }^{4}$. Elevated levels of proinflammatory and procoagulant factors have been observed in chronic $H$. pylori infected subjects which might be responsible for increase stroke risk in these individuals ${ }^{4,5}$. Chronic $H$ pylori infection is associated with elevated C-reactive protein, total cholesterol, plasma fibrinogen levels, and IL-8

\footnotetext{
${ }^{1}$ Department of Neurology and Ophthalmology, Michigan State University.

Correspondência para / Correspondence to:

Muhammad U Farooq, MD.

Department of Neurology. A-217 Clinical Center. Michigan State University.

East Lansing, MI 48824 USA.

Phone: 517-353-8122. Fax: 517-432-9414.

E-mail: muhammad.farooq@ht.msu.edu
} 
levels. These elevate the risk of atherosclerosis, increase blood viscosity, promote blood clot formation and induce a systemic vasculopathy resulting in cerebrovascular accident $t^{4}$.

H. pylori seropsitivity has been associated with increased risk of atherothrombotic, lacunar and microangiopathic strokes ${ }^{7-12}$. However, a small, case control study did not found an increased risk of stroke with $H$. pylori seropositivity in multivariate analysis ${ }^{13}$. $H$. pylori strains having the cytotoxin-associated gene-A (CagA) are associated with increased inflammation ${ }^{14,15}$. The increased titer of antibodies against these particular strains are seen in large vessel strokes ${ }^{14}$. There is a molecular mimicry between antigen determinants of CagA positive strains and endothelial cells of blood vessels ${ }^{15}$. Therefore antibodies against CagA cross-react with vascular wall antigens which might be a potential mechanism of initima-media thickness and atherosclerosis linked with CagA strain ${ }^{15,16}$. H. pylori has been detected in carotid plaques and has shown to be associated with upregulated adhesion receptors ${ }^{17,18}$. Infection with CagA strains in atherosclerotic stroke patients is associated with greater intima-media thickness, plaque instability, acute cerebral ischemia and poorer short-term outcome compared with $\operatorname{Cog} A$ negative patients ${ }^{19-21}$. However, another study showed that H. pylori and the CagA strain are not major risk factors for early arteriosclerosis as assessed by carotid artery intima-media thickness ${ }^{22}$.

Mild cognitive impairment and Alzheimer's disease

The association of mild cognitive impairment and Alzheimer's disease (AD) with underlying microbial infection has been addressed by recent studies ${ }^{23,24}$. H. pylori infection is linked to different cognitive and memory problems including $A D^{25-28}$. Kountouras et al. investigated this association in their studies ${ }^{28,29}$. The rate of $H$. pylori infection was found to be higher in AD patients than the ones in control group. Different mechanisms have been proposed which might be responsible for this association. The autoimmune response can be triggered due to the molecular mimicry between $H$. pylori cellular antigens and different components of nervous tissues. Different other mechanisms as a result of induction of different cellular and humoral immune responses including the release of excessive amounts of pro-inflammatory substances including ILs-6, 8, 10 and 12; tumor necrosis factor; interferon-gamma; leukotrienes and prostaglandins; acute phase proteins like fibrinogen and $C$-reactive proteins; reactive oxygen species and free radicals have also been proposed to explain the $H$. pylori association with $A D^{25,29}$. H. pylori infection might also influence the apoptotic process, promote platelet-leukocyte aggregation, increase homocysteine levels and damage the endothelial lining of blood vessels influencing the pathophysiology of different neurodegenerative disorders like $A D^{25,28}$. The elevated levels of homocystine are linked to atrophic gastritis which can lead to malabsorption of vitamin $B 12$ and folate resulting in failure of methylation by 5-methyl-tetrahydrofolate $e^{30}$. Keeping in view this association of $H$. pylori infection and $A D$, eradication of $H$. pylori infection in patients with mild cognitive impairment and $A D$ might delay their disease progression $^{28}$.

\section{Parkinson's disease}

H. pylori infection might be associated with neurodegenerative conditions like idiopathic Parkinson's disease $(P D)^{31-38}$. It has been reported that the gastrointestinal tracts of $P D$ patients are more vulnerable to develop peptic ulcer and similar syndromes than the ordinary people of the same age ${ }^{39}$. Strang found that $15 \%$ of 200 consecutive patients with PD had a history of peptic ulcer compared with $4 \%$ of controls ${ }^{31}$. Charlett et al. described the linkage between the prevalence of $H$. pylori and of parkinsonism to the source of drinking water ${ }^{40}$. The exact underlying mechanism of this association is not well defined but the acquired immunosuppression due to chronic peripheral inflammation and the resulting 
auto-immunity might be a key factor in its pathogenesis ${ }^{33}$.

H. pylori infection can affect the absorption of levo-dopa in patients with PD by different direct and indirect mechanisms ${ }^{41}$. $H$. pylori mainly causes antral predominant gastritis resulting in hypersecretion of gastric acid and disruption of duodenal mucosa effecting the solubility and impaired absorption of levo-dopa $a^{42,43}$. H. pylori eradication may improve clinical response to levo-dopa by modifying its pharmacokinetics ${ }^{44,45}$. Pierantozzi et al. has recently investigated the short and long-term clinical effects of $H$. pylori eradication and showed that it improved the clinical status of infected PD patients and induced a more stable and long-lasting response to levo-dopa $a^{43}$. The prolonged high plasma levodopa concentration was found in eradicated patients. The present studies suggest that $H$. pylori eradication may represent an excellent therapeutic opportunity and can play a effective clinical role in PD patients by reducing the motor fluctuations and by increasing the "on" time period duration ${ }^{43}$.

\section{Seizure disorders}

There is a possible association of $H$. pylori infection with different seizure disorders ${ }^{46,47}$. Okuda et al. investigated the rate of $H$. pylori infection in patients with epilepsy and seizure disorder ${ }^{46}$. They enrolled 75 epilepsy patients and 71 chronic disease patients in their study. The influence of $H$. pylori infection on prognosis of these patients was also monitored in this study ${ }^{46}$. The epileptic patients with H. pylori showed poor prognosis as compared with noninfected patients. The proposed mechanism involved antibodies against cardiolipin, an important phospholipid in the membranes of H. pylori ${ }^{46,48}$. The production of autoantibodies due to the cross-mimicry between $H$. pylori and cellular phospholipids might be responsible for chronic activation of different inflammatory pathways and release of different proinflammatory substances ${ }^{46}$. The increase prevalence of autoantibodies in seizure patients and gradual resolution of neurological symptoms after $H$. pylori eradication has been seen in other studies ${ }^{49-51}$.

Ozturk et al. studied the presence of $H$. pylori infection in seizure patients for the possible trigger effect of seizure via immunological mechanisms ${ }^{47}$. Their findings supported that $H$ pylori infection might trigger epilepsy by immunological mechanisms as shown by other studies before ${ }^{47}$. They proposed that $H$. pylori stool antigen test can be used to identify active $H$ pylori infections in patients with seizure disorders.

\section{Multiple sclerosis and peripheral neuropathies}

H. pylori infections has been linked to multiple sclerosis (MS) and demyelinating peripheral neuropathies as it can trigger cellular and humoral immunity due to the sharing of similar epitopes present in the nervous tissue ${ }^{52,53}$. These antibodies cross-react with different components of central and peripheral nerves resulting in their damage. Many other factors like platelet activation and aggregation; different vasoactive and inflammatory substances; stimulation of mononuclear cells to produce different tissue factor-like procoagulants; reactive oxygen species; and apoptotic processes may be important factors in the association of $H$. pylori infection with $M S$ and peripheral neuropathies like GuillainBarre syndrome ${ }^{52,53}$.

Li et al. studied the prevalence of $H$ pylori infection in different MS subtypes including classic (CMS) and opticospinal MS (OSMS) in the Japanese population and demonstrated a difference in $H$. pylori seropositivity between Japanese patients with OSMS and those with CMS. H. pylori infection was significantly lower in patients with CMS than in healthy controls or patients with OSMS ${ }^{54}$. This study suggested that the differences in childhood environment might exert distinct effects on the development of each MS subtype later in life and $H$ pylori might be a protective factor against CMS

Wenderet al. also reported lower frequency of $H$. pylori infection in MS as compared with controls ${ }^{55}$. 
Cephalgia

There are different opinions about the association of $H$. pylori infection and different headache syndromes. High prevalence of $H$. pylori has been reported in individuals with different headache types and its eradication significantly decreased headache attacks ${ }^{56-59}$. There is a significantly higher prevalence of CagA-positive H. pylori strains in patients with migraine with aura ${ }^{58}$. Other studies have demonstrated that chronic $H$. pylori infection is not more frequent in patients with migraine than in controls ${ }^{60}$. Different mechanisms including cerebral blood flow changes, production of antioxidants, and other immune function alterations have been proposed as possible mechanisms of headache and migraine in $H$. pylori positive subjects ${ }^{6}$. However, a recent study did not support the role of oxidative stress in migraine patients suffering from $\mathrm{H}$. pylori infection $^{61}$.

Non-arteritic anterior ischemic optic neuropathy and glaucoma

H. pylori is associated with different ophthalmological and neuron-ophthalmological problems like non-arteritic anterior ischemic optic neuropathy, primary open angel and exfoliation glaucoma ${ }^{26,32,62-66}$. There may be a causal link between H. pylori and glaucoma ${ }^{62,63}$. Anti-H. pylori antibodies cross-react with ciliary body epithelial antigens and it also induces apoptosis in trabecular meshwork. Other pathophysiological mechanisms may involve pro-inflammatory vasoactive substances and induction of apoptosis resulting in glaucomatous neuropathy ${ }^{62,65}$. High prevalence of $H$. pylori has been documented in glaucoma patients by different studies ${ }^{62,63}$. Eradication of $H$. pylori showed improvement in different glaucoma parameters including mean intraocular pressure and visual fields parameters ${ }^{63}$. Kountouras et al. showed the high levels of $H$. pylori specific IgG antibody levels in the aqueous humor of patients with primary open angel glaucoma and exfoliation glaucoma ${ }^{64}$. The titers of anti-H. pylori antibody in aqueous humor might reflect the severity of disease in patients with primary open angel glaucoma according to this study $y^{64}$. However, other studies did not show any statistically significant association of $H$. pylori infection with open angel glaucoma ${ }^{67}$.

\section{CONCLUSIONS}

H. pylori plays a potential role in the pathophysiology of many neurological and ophthalmological disorders. The current data is very limited to establish any causal relationship between $H$. pylori and most of the above mentioned disorders. The long-term effects of $H$. pylori eradication therapy on the course of these disorders are not clear and there is a need for further research to establish this association.

\section{Helicobacter pylori: transtornos neurológicos e oftalmológicos}

\section{Resumo}

A infecção por Helicobacter pylori tem sido associada a muitas infecçōes intestinais e extra-intestinais. Tem sido relacionada com muitas doenças neurológicas e oftalmológicas, incluindo as doenças cerebrovasculares, enxaqueca, doença de Alzheimer, epilepsia, doença de Parkinson, esclerose múltipla, neuropatias periféricas, glaucoma, e neuropatia ótica isquêmica. Os mecanismos fisiopatológicos podem envolver vários processos imunológicos em resposta a um agente infeccioso ou diferentes antígenos liberados durante a destruição do tecido, resultando em ativação da imunidade celular e humoral; ativação e agregação plaquetária; diferentes substâncias vasoativas e inflamatórias; espécies reativas de oxigênio e processos apoptóticos. Os efeitos a longo prazo do $H$. pylori no curso desses transtornos ainda precisam ser explorados.

Palavras-chave: Helicobacter pylori - Doenças cerebrovasculares - Doença de Alzheimer - Doença de Parkinson - Enxaqueca - Convulsões - Esclerose múltipla - Neuropatias periféricas - Glaucoma. 


\section{REFERENCES}

1 Realdi G, Dore MP, Fastame L: Extradigestive manifestations of helicobacter pylori infection: Fact and fiction. Dig Dis Sci 1999;44:229-236.

2 Gasbarrini A, Franceschi F, Armuzzi A et al.: Extradigestive manifestations of helicobacter pylori gastric infection. Gut 1999;45 Suppl 1:I9-I12.

3 Tsang KW, Lam SK: Extragastroduodenal conditions associated with helicobacter pylori infection. Hong Kong Med J 1999;5:169-174.

4 Majka J, Rog T, Konturek PC, et al: Influence of chronic helicobacter pylori infection on ischemic cerebral stroke risk factors. Med Sci Monit 2002;8:CR675-684.

5 Laurila A, Bloigu A, Nayha S, et al: Association of helicobacter pylori infection with elevated serum lipids. Atherosclerosis 1999;142:207210 .

6 Bodger K, Crabtree JE: Helicobacter pylori and gastric inflammation. Br Med Bull 1998;54:139-150.

7 Markus HS, Mendall MA: Helicobacter pylori infection: A risk factor for ischaemic cerebrovascular disease and carotid atheroma. J Neurol Neurosurg Psychiatry 1998;64:104107.

8 Grau AJ, Buggle F, Lichy C, et al: Helicobacter pylori infection as an independent risk factor for cerebral ischemia of atherothrombotic origin. J Neurol Sci 2001;186:1-5.

9 Heuschmann PU, Neureiter D, Gesslein M, $\mathrm{C}$ et al: Association between infection with helicobacter pylori and chlamydia pneumoniae and risk of ischemic stroke subtypes: Results from a population-based case-control study. Stroke 2001;32:2253- 2258.

10 Ponzetto A, Marchet A, Pellicano R, et al: Association of helicobacter pylori infection with ischemic stroke of non-cardiac origin: The bat.Ma.N. Project study. Hepatogastroenterology 2002;49:631-634.
11 Sawayama Y, Ariyama I, Hamada M, et al: Association between chronic helicobacter pylori infection and acute ischemic stroke: Fukuoka harasanshin atherosclerosis trial (fhat). Atherosclerosis 2005;178:303-309.

12 Masoud SA, Arami MA, Kucheki E: Association between infection with helicobacter pylori and cerebral noncardioembolic ischemic stroke. Neurol India 2005;53:303-306; discussion 306-307.

13 Whincup PH, Mendall MA, Perry IJ, Strachan DP, Walker M: Prospective relations between helicobacter pylori infection, coronary heart disease, and stroke in middle aged men. Heart 1996;75:568-572.

14 Pietroiusti A, Diomedi M, Silvestrini M, et al: Cytotoxin-associated gene-a-positive helicobacter pylori strains are associated with atherosclerotic stroke. Circulation 2002;106:580-584.

15 Franceschi F, Sepulveda AR, Gasbarrini A, et al: Cross-reactivity of anti-caga antibodies with vascular wall antigens: Possible pathogenic link between helicobacter pylori infection and atherosclerosis. Circulation 2002;106:430-434.

16 Pietroiusti A: Role of caga positive helicobacter pylori strains in ischemic heart disease and in ischemic stroke. Ital Heart J 2002;3:626-628.

17 Farsak B, Yildirir A, Akyon Y, et al: Detection of chlamydia pneumoniae and helicobacter pylori DNA in human atherosclerotic plaques by pcr. J Clin Microbiol 2000;38:4408-4411.

18 Ameriso SF, Fridman EA, Leiguarda RC, Sevlever GE: Detection of helicobacter pylori in human carotid atherosclerotic plaques. Stroke 2001;32:385-391.

19 Diomedi M, Pietroiusti A, Silvestrini M, et al: Caga-positive helicobacter pylori strains may influence the natural history of atherosclerotic stroke. Neurology 2004;63:800-804.

20 Preusch MR, Grau AJ, Buggle F, et al: Association between cerebral ischemia and cytotoxin-associated gene-a-bearing strains of helicobacter pylori. Stroke 2004;35:1800-1804. 
21 Gabrielli M, Santoliquido A, Cremonini F, et al: Caga-positive cytotoxic h. Pylori strains as a link between plaque instability and atherosclerotic stroke. Eur Heart J 2004;25:6468.

22 Markus HS, Risley P, Mendall MA, Steinmetz H, Sitzer M: Helicobacter pylori infection, the cytotoxin gene a strain, and carotid artery intima-media thickness. J Cardiovasc Risk 2002;9:1-6.

23 Itzhaki RF, Wozniak MA, Appelt DM, Balin BJ: Infiltration of the brain by pathogens causes Alzheimer's disease. Neurobiol Aging 2004;25:619-627.

24 Kinoshita J: Pathogens as a cause of Alzheimer's disease. Neurobiol Aging 2004;25.

25 Kountouras J, Gavalas E, Zavos C, et al: Alzheimer's disease and helicobacter pylori infection: Defective immune regulation and apoptosis as proposed common links. Med Hypotheses 2007;68:378-388.

26 Kountouras J, Zavos C, Gavalas E, et al: Normal-tension glaucoma and Alzheimer's disease: Helicobacter pylori as a possible common underlying risk factor. Med Hypotheses 2007;68:228-229.

27 Malaguarnera M, Bella R, Alagona G, et al: Helicobacter pylori and Alzheimer's disease: A possible link. Eur J Intern Med 2004;15:381386.

28 Kountouras J, Tsolaki M, Boziki M, et al: Association between helicobacter pylori infection and mild cognitive impairment. Eur J Neurol 2007;14:976-982.

29 Kountouras J, Tsolaki M, Gavalas E, et al: Relationship between helicobacter pylori infection and Alzheimer disease. Neurology 2006;66:938-940.

30 Santarelli L, Gabrielli M, Cremonini F, et al: Atrophic gastritis as a cause of hyperhomocysteinaemia. Aliment Pharmacol Ther 2004;19:107-111.

31 Strang RR: The association of gastroduodenal ulceration and Parkinson's disease. Med J Aust 1965;310:842-843.
32 Altschuler E: Gastric helicobacter pylori infection as a cause of idiopathic Parkinson disease and non-arteric anterior optic ischemic neuropathy. Med Hypotheses 1996;47:413414.

33 Dobbs SM, Dobbs RJ, Weller C, Charlett A: Link between helicobacter pylori infection and idiopathic parkinsonism. Med Hypotheses 2000;55:93-98.

34 Weller C, Oxlade N, Dobbs SM, et al: Role of inflammation in gastrointestinal tract in aetiology and pathogenesis of idiopathic parkinsonism. FEMS Immunol Med Microbiol 2005;44:129-135.

35 Dobbs RJ, Dobbs SM, Weller C, et al: Role of chronic infection and inflammation in the gastrointestinal tract in the etiology and pathogenesis of idiopathic parkinsonism. Part 1: Eradication of helicobacter in the cachexia of idiopathic parkinsonism. Helicobacter 2005; 10:267-275.

36 Bjarnason IT, Charlett A, Dobbs RJ, et al. Role of chronic infection and inflammation in the gastrointestinal tract in the etiology and pathogenesis of idiopathic parkinsonism. Part 2: Response of facets of clinical idiopathic parkinsonism to helicobacter pylori eradication. A randomized, double-blind, placebocontrolled efficacy study. Helicobacter 2005;10:276-287.

37 Weller C, Charlett A, Oxlade NL, et al: Role of chronic infection and inflammation in the gastrointestinal tract in the etiology and pathogenesis of idiopathic parkinsonism. Part 3: Predicted probability and gradients of severity of idiopathic parkinsonism based on h. Pylori antibody profile. Helicobacter 2005; 10:288297.

38 Schulz JD, Hawkes EL, Shaw CA: Cycad toxins, helicobacter pylori and parkinsonism: Cholesterol glucosides as the common denomenator. Med Hypotheses 2006;66:12221226.

39 Schwab RS: Symptomatology and medical treatment of Parkinson's disease. Int J Neurol 1961;2:61-75. 
40 Charlett A, Dobbs RJ, Dobbs SM, et al: Parkinsonism: Siblings share helicobacter pylori seropositivity and facets of syndrome. Acta Neurol Scand 1999;99:26-35.

41 Milman N, Rosenstock S, Andersen L, et al: Serum ferritin, hemoglobin, and helicobacter pylori infection: A seroepidemiologic survey comprising 2794 Danish adults. Gastroenterology 1998;115:268-274.

42 Kurlan R, Nutt JG, Woodward WR, et al: Duodenal and gastric delivery of levodopa in parkinsonism. Ann Neurol 1988;23:589-595.

43 Pierantozzi M, Pietroiusti A, Brusa L, et al: Helicobacter pylori eradication and l- dopa absorption in patients with pd and motor fluctuations. Neurology 2006;66:1824- 1829.

44 Pierantozzi M, Pietroiusti A, Galante A, et al: Helicobacter pylori-induced reduction of acute levodopa absorption in Parkinson's disease patients. Ann Neurol 2001;50:686-687.

45 Pierantozzi M, Pietroiusti A, Sancesario G, et al: Reduced l-dopa absorption and increased clinical fluctuations in helicobacter pyloriinfected Parkinson's disease patients. Neurol Sci 2001;22:89-91.

46 Okuda M, Miyashiro E, Nakazawa T, Minami K, Koike M: Helicobacter pylori infection and idiopathic epilepsy. Am J Med 2004;116:209-210.

47 Ozturk A, Ozturk CE, Ozdemirli B, Yucel M, Bahcebasi T: Helicobacter pylori infection in epileptic patients. Seizure 2007;16:147152.

48 Hirai Y, Haque M, Yoshida T, et al: Unique cholesteryl glucosides in helicobacter pylori: Composition and structural analysis. J Bacteriol 1995; 177:5327-5333.

49 Verrot D, San-Marco M, Dravet C, et al: Prevalence and signification of antinuclear and anticardiolipin antibodies in patients with epilepsy. Am J Med 1997;103:33-37.

50 Peltola JT, Haapala A, Isojarvi JI, et al: Antiphospholipid and antinuclear antibodies in patients with epilepsy or new-onset seizure disorders. Am J Med 2000;109:712- 717.
51 Cicconi V, Carloni E, Franceschi F, et al: Disappearance of antiphospholipid antibodies syndrome after helicobacter pylori eradication. Am J Med 2001;111:163- 164.

52 Kountouras J, Deretzi G, Zavos C, et al: Association between helicobacter pylori infection and acute inflammatory demyelinating polyradiculoneuropathy. Eur J Neurol 2005;12:139-143.

53 Gavalas E, Kountouras J, Deretzi G, et al.: Helicobacte pylori and multiple sclerosis. J Neuroimmunol 2007;188:187-189.

$54 \mathrm{Li}$ W, Minohara M, Su JJ, et al: Helicobacter pylori infection is a potential protective factor against conventional multiple sclerosis in the Japanese population. J Neuroimmunol 2007;184:227-231.

55 Wender M: [prevalence of helicobacter pylori infection among patients with multiple sclerosis]. Neurol Neurochir Pol 2003;37:4548.

56 Gasbarrini A, De Luca A, Fiore G, et al: Primary headache and helicobacter pylori. Int J Angiol 1998;7:310-312.

57 Gasbarrini A, De Luca A, Fiore G, et al: Beneficial effects of helicobacter pylori eradication on migraine. Hepatogastroenterology 1998;45:765-770.

58 Gasbarrini A, Gabrielli M, Fiore G, Candelli $\mathrm{M}$, et al: Association between helicobacter pylori cytotoxic type i caga-positive strains and migraine with aura. Cephalalgia 2000;20:561565 .

59 Tunca A, Turkay C, Tekin O, Kargili A, Erbayrak M: Is helicobacter pylori infection a risk factor for migraine? A case-control study. Acta Neurol Belg 2004;104:161-164.

60 Pinessi L, Savi L, Pellicano R, et al: Chronic helicobacter pylori infection and migraine: $\mathrm{A}$ case-control study. Headache 2000;40:836839.

61 Tunca A, Karanfil A, Koktener A, Kargili A, Tekin O: Association between mitral annular calcification and stroke. Jpn Heart J 2004;45:999-1005. 
62 Kountouras J, Mylopoulos N, Boura P, et al: Relationship between helicobacter pylori infection and glaucoma. Ophthalmology 2001;108:599-604.

63 Kountouras J, Mylopoulos N, Chatzopoulos $\mathrm{D}$, et al: Eradication of helicobacter pylori may be beneficial in the management of chronic open-angle glaucoma. Arch Intern Med 2002;162:1237-1244.

64 Kountouras J, Mylopoulos N, Konstas AG, et al: Increased levels of helicobacter pylori igg antibodies in aqueous humor of patients with primary open-angle and exfoliation glaucoma. Graefes Arch Clin Exp Ophthalmol 2003;241:884-890.
65 Kountouras J, Zavos C, Chatzopoulos D: Induction of apoptosis as a proposed pathophysiological link between glaucoma and helicobacter pylori infection. Med Hypotheses 2004;62:378-381.

66 Zavos C, Kountouras J, Skoura L, Sakkias G, Parapanisiou E: Mitogen-activated protein kinase (mapk) intracellular signalling in the aqueous humour activated by helicobacter pylori may have a role in glaucoma. Med Hypotheses 2007;68:928-929.

67 Galloway PH, Warner SJ, Morshed MG, Mikelberg FS: Helicobacter pylori infection and the risk for open-angle glaucoma. Ophthalmology 2003;110:922-925. 